\title{
Amaurosis fugax under the age of 40 years
}

\author{
C J M POOLE, R W ROSS RUSSELl, P HARRISON, G F SAVIDGE \\ From the Departments of Neurology, Medical Ophthalmology and Coagulation, St Thomas's Hospital, \\ London, UK
}

\begin{abstract}
SUMMARY Sixteen patients who presented under the age of 40 years with amaurosis fugax have been studied. Follow up from the time of presentation was one to 13 years with a median of 3 years. One patient whose attacks of uniocular visual loss were associated with headache developed a permanent uniocular field defect. None of the other patients has suffered permanent visual loss, or had symptoms of cerebral or myocardial ischaemia. All angiograms were normal and it is suggested that carotid angiography is unnecessary in this age group. Four out of ten patients studied demonstrated evidence of platelet hyperaggregability to low concentrations of arachidonic acid and adenosine diphosphate with spontaneous aggregation. However, in six patients treated with aspirin, including three with previous platelet hyperaggregability, there was no change in the frequency of their attacks implying that the observed platelet abnormalities were not the cause of the amaurosis fugax.
\end{abstract}

Amaurosis fugax usually affects the middle-aged and elderly and is commoner in men. ${ }^{1}$ It is thought to be caused by emboli of fibrin-platelet aggregates derived from atheromatous lesions of the carotid artery or from the cardiac valves. In our previous study of amaurosis fugax $10 \%$ of patients were under the age of 40 when they presented. ${ }^{2}$ Advanced atherosclerotic carotid artery disease is unlikely to be present in this age group and no significant cardiac lesions were detected. Eadie, et al reported 12 patients between the ages of 14 and 51 years with amaurosis fugax of whom eight had carotid arteriograms all of which were normal; none had cardiological investigations and they suggested that uniocular visual loss was benign in this age group. ${ }^{3}$

Amaurosis fugax has been reported in patients with secondary thrombocytosis and essential thrombocythaemia ${ }^{4}$ Treatment with aspirin $325 \mathrm{mg}$ tid and persantin $100 \mathrm{mg}$ tid returned the haematological abnormalities to normal and abolished the amaurosis fugax in the few patients described.

Increased platelet aggregation with normal total platelet counts has been found in patients during the interval and prodromal phases of migraine, ${ }^{56}$ in oph-

Address for reprint requests: Dr CJM Poole, Medical Unit, Westminster Hospital, 17 Page Street, London SWIP 2AP, UK

Received 6 December 1985 and in revised form 19 April 1986. Accepted 25 April 1986. thalmoplegic migraine, ${ }^{7}$ cerebral transient ischaemic attacks and after cerebral infarcts. ${ }^{89}$ We report here some aspects of platelet function in a group of young patients with amaurosis fugax to determine whether a primary platelet disorder was contributing to or responsible for their symptoms.

\section{Patients and methods}

All 16 patients had been seen either at Moorfields Eye Hospital, Royal Eye Hospital, or St Thomas's Hospital, London between 1971 and 1984. Amaurosis fugax was defined as partial or complete uniocular visual loss of sudden onset lasting less than one hour. Patients with overt ocular pathology, glaucoma or over the age of $\mathbf{4 0}$ years were excluded for the purpose of this study.

From hospital records and the patients themselves the following information was obtained: age at presentation to hospital; maximum frequency of the attacks per month; precipitating factors or associated features such as headache or gastro-intestinal disturbance. A personal history of migraine and a drug history including use of the oral contraceptive pill was noted. Investigations included full blood count, platelet count, ESR, serum VDRL/TPHA, an electrocardiogram, an echocardiogram and carotid arteriography.

Ten of the 16 patients, those who had experienced symptoms within the previous 6 months, had platelet aggregation studies and estimation of platelet release proteins performed. Medication was discontinued 2 weeks prior to the initial platelet studies. Venous blood was collected by a two syringe technique from an antecubital vein using a 19 gauge needle. 
To prepare platelet rich plasma (PRP) the blood was mixed immediately with anticoagulant $(9 \mathrm{vol}$ blood to 1 vol $0 \cdot 11 \mathrm{M}$ trisodium citrate) and centrifuged at $45 \mathrm{~g}$ for 20 minutes at room temperature. After aspirating the PRP, the remaining plasma was centrifuged at $200 \mathrm{~g}$ for 10 minutes at room temperature to obtain platelet poor plasma (PPP). Samples for estimation of platelet release proteins were prepared from venous blood added to theophylline/EDTA anticoagulant ( 9 vols blood to 1 vol anticoagulant). After cooling for 15 minutes at $4^{\circ} \mathrm{C}$, the samples were centrifuged at $2000 \mathrm{~g}$ at $4^{\circ} \mathrm{C}$ for 30 minutes and the middle third of the plasma supernatant aspirated and stored in $500 \mu \mathrm{l}$ aliquots at $-80^{\circ} \mathrm{C}$ until assaying within 4 weeks of collection. Control samples were collected from healthy donors in an identical manner, in the same department and studied simultaneously with the patient samples.

Platelet aggregometry was performed by conventional techniques using a PAP-4 aggregometer (Biodata, Hatboro, USA) with computerised analysis of the aggregation profiles based upon the kinetics of aggregation. Aggregating agents included $0.34 \mathrm{mM}, 1.3 \mathrm{mM}$ and $3.4 \mathrm{mM}$ sodium arachidonate (Sigma, Poole, Dorset) and $0.5 \mu \mathrm{M}, 1.0 \mu \mathrm{M}$ and $2.0 \mu \mathrm{M}$ adenosine diphosphate (BDH, Dagenham, Essex). Spontaneous aggregation was assessed by aggregation observed over a 15 minute period without the addition of aggregating agents. Any spontaneous aggregation is abnor$\mathrm{mal}$ in this laboratory. Platelet release proteins were estimated using commercially available kits: $\beta$-thromboglobulin $(\beta-\mathrm{TG})$ from Amersham International, Bucks, England; platelet factor 4 (PF4) from Abbot Laboratories, Chicago, USA and thromboxane B2 (TxB) from New England Nuclear, Southampton, England. Those patients with spontaneous aggregation or hyperaggregability to arachidonic acid (AA) had aggregation studies with adenosine diphosphate (ADP) and platelet release protein estimations.

\section{Results}

The 16 patients comprised 11 females and five males with a mean age of 25 years ( 5 to 37). The frequency of attacks ranged from five per week to one per year (table 1). Three had been 9-10 years without recurrence. In eight the right eye only was affected, in two the left and in six either eye. Loss of vision was described in some as a dazzle effect. Others described a centripetal or centrifugal pattern of darkening and in two the "curtain" effect from above or below. The duration of visual loss was from a few seconds to a few minutes in all but one patient who reported amaurosis lasting $\mathbf{4 0}$ minutes. Five noticed discomfort or paraesthesiae in or round the affected eye one or two seconds before the onset of the attack. Two had attacks associated with headache. Possible precipitating factors were leaning forward, bright lights or menstruation. Three women took the oral contraceptive pill.

There was no evidence of neurological or cardiovascular disease in any patient apart from one with mild hypertension and another with a systolic cardiac murmur. Ophthalmoscopy was normal in all patients including one who was examined during an episode of visual loss. This patient did have however a relative afferent pupil defect on the affected side during the attack. Ophthalmodynamometry was normal in all patients.

One patient (BM) pursued an atypical course. She had had amaurosis fugax from the age of 13 years. Sometimes the attack was associated with temporal headache and nausea. On one occasion, whilst cooking, her vision did not recover in the usual way, due to a sectorial field defect in the affected eye. There was no associated headache on this occasion. She was not taking the..oral contraceptive pill and the only past medical history of note was classical migraine which developed in her late 20s. Fluorescein angiography showed a narrowed and irregular retinal artery with

Table 1 Distribution of patients according to sex, age, duration of follow up and maximum frequency of attacks

\begin{tabular}{|c|c|c|c|c|c|c|}
\hline & Patient & Sex & $\begin{array}{l}\text { Age at } \\
\text { presentation } \\
\text { (years) }\end{array}$ & $\begin{array}{l}\text { Duration of } \\
\text { follow up } \\
\text { (years) }\end{array}$ & $\begin{array}{l}\text { Maximum } \\
\text { frequency/ } \\
\text { month }\end{array}$ & Comments \\
\hline $\begin{array}{r}1 \\
2 \\
3 \\
4 \\
5 \\
6 \\
7 \\
8 \\
9 \\
10\end{array}$ & $\begin{array}{l}\text { SR } \\
\text { CM } \\
\text { JJ } \\
\text { JM } \\
\text { HG } \\
\text { AC } \\
\text { CE } \\
\text { MS } \\
\text { BL } \\
\text { BM }\end{array}$ & $\begin{array}{l}\mathbf{M} \\
\mathbf{F} \\
\mathbf{M} \\
\mathbf{F} \\
\mathbf{M} \\
\mathbf{F} \\
\mathbf{F} \\
\mathbf{F} \\
\mathbf{M} \\
\mathbf{F}\end{array}$ & $\begin{array}{l}18 \\
23 \\
27 \\
22 \\
28 \\
23 \\
26 \\
21 \\
21 \\
37\end{array}$ & $\begin{array}{r}13 \\
10 \\
10 \\
9 \\
7 \\
5 \\
4 \\
3 \\
3 \\
3\end{array}$ & $\begin{array}{l}10 \\
1-2 \\
20 \\
<1 \\
1-2 \\
2-3 \\
<1 \\
2 \\
1-2 \\
<1\end{array}$ & $\begin{array}{l}\text { Still occurring } \\
6 \text { attacks all whilst pregnant. None since. } \\
\text { None for the last } 9 \text { years. } \\
\text { None for the last } 9 \text { years. } \\
\text { Still occurring. } \\
\text { West Indian. Sickle test negative. Still occurring. } \\
\text { None for } 12 \text { months. } \\
\text { Still occurring. RAPD during attack. } \\
\text { West Indian. Sickle test negative. Still occurring. } \\
\text { Still occurring. Permanent visual field defect. } \\
\text { Classical migraine. }\end{array}$ \\
\hline $\begin{array}{l}11 \\
12 \\
13 \\
14 \\
15 \\
16\end{array}$ & $\begin{array}{l}\text { AM } \\
\text { RC } \\
\text { AW } \\
\text { SB } \\
\text { MH } \\
\text { RS }\end{array}$ & $\begin{array}{l}\mathbf{F} \\
\mathbf{F} \\
\mathbf{F} \\
\mathbf{M} \\
\mathbf{F}\end{array}$ & $\begin{array}{r}20 \\
5 \\
28 \\
23 \\
37 \\
36\end{array}$ & $\begin{array}{l}2 \\
1 \\
1 \\
1 \\
1 \\
1\end{array}$ & $\begin{array}{l}1-2 \\
<1 \\
8 \\
1-2 \\
2-3\end{array}$ & $\begin{array}{l}\text { Still occurring. } \\
\text { West Indian. Daughter of AC. } \\
2 \text { attacks only. } \\
\text { Occur pre-menstrually. Raynaud's disease. } \\
\text { Raynaud's disease. }\end{array}$ \\
\hline
\end{tabular}

RAPD = relative afferent pupil defect. 


\begin{tabular}{|c|c|c|c|c|c|c|c|c|c|c|}
\hline \multirow[b]{2}{*}{ Name } & \multirow{2}{*}{$\begin{array}{l}\text { Spontaneous } \\
\text { aggregation }\end{array}$} & \multicolumn{3}{|c|}{ Arachidonic acid aggregation } & \multicolumn{3}{|c|}{ ADP aggregation } & \multirow{2}{*}{$\begin{array}{l}\beta T G \\
(n g / m l)\end{array}$} & \multirow{2}{*}{$\begin{array}{l}P F 4 \\
(n g / m l)\end{array}$} & \multirow{2}{*}{$\begin{array}{l}T x B \\
(p g / m l)\end{array}$} \\
\hline & & $0.34 \mathrm{mM}$ & $1.3 \mathrm{mM}$ & $3.4 \mathrm{mM}$ & $0.5 \mu M$ & $1 \mu M$ & $2 \mu M$ & & & \\
\hline $\begin{array}{l}\text { Normal } \\
\text {-1. AC }\end{array}$ & - & - & \pm & + & - & \pm & + & $<52$ & $<10.4$ & $<40.0$ \\
\hline a) >1 week post attack & + & - & - & + & - & + & + & 19 & $8 \cdot 5$ & $19 \cdot 8$ \\
\hline $\begin{array}{l}\text { b) } 2 \text { hours post attack } \\
\text { c) On } 75 \mathrm{mg} \text { sol. aspirin daily } \\
\text { 2. MH }\end{array}$ & $\stackrel{+}{-}$ & + & + & + & \pm & \pm & \pm & & 6.8 & 20.0 \\
\hline a) $>$ I week post attack & - & - & + & + & - & + & + & $>225$ & $>100$ & $25 \cdot 0$ \\
\hline b) $>1$ week post attack & - & + & + & + & + & + & + & $>225$ & $>100$ & $26 \cdot 7$ \\
\hline 3. $\mathbf{B M}$ & - & + & + & + & - & + & + & & $6 \cdot 2$ & $21 \cdot 0$ \\
\hline 4. $\mathrm{RC}$ & + & - & + & + & + & + & + & 54 & $20 \cdot 0$ & 20.0 \\
\hline $\begin{array}{l}\text { 5. BL } \\
6 . \mathrm{AM}\end{array}$ & - & - & + & + & & - & + & 28 & $4 \cdot 3$ & 44.9 \\
\hline a) >1 week post attack & - & - & - & + & & & & & & \\
\hline b) 12 hours post attack & - & - & + & + & & & & & & \\
\hline 7. AW & - & - & - & + & & & & & & \\
\hline 8. LE & - & - & - & + & & & & & & \\
\hline 9. SB & - & - & - & + & & & & & & \\
\hline 10. HG & - & - & - & + & & & & & & \\
\hline
\end{tabular}

+ = aggregation observed; - = no aggregation observed .

focal leakage of fluorescein. Three years later she still has a residual sectorial field defect and continues to experience amaurosis fugax in the same eye.

All patients had a normal full blood count, peripheral platelet count, ESR, and serum VDRL and TPHA. Carotid arteriography (including four digital subtraction angiograms after iv injection) was normal in the 10 patients who underwent this investigation. Fourteen patients had echocardiography which was normal in all cases. No patient had cardiac disease, hypertension, diabetes, evidence of arteritis or polycythaemia. Five smoked cigarettes and two had cold sensitivity of the Raynaud type.

The results of spontaneous platelet aggregation, platelet aggregation with AA and ADP and platelet release protein concentrations are shown in table 2 . One patient (AC) was studied 2 hours after an attack when spontaneous platelet aggregation and platelet hyperaggregability to low concentrations of $\mathbf{A A}$ and ADP could be demonstrated. When these tests were repeated one week after her previous attack, spontaneous platelet aggregation was still present but there was no evidence of hyperaggregability to AA or ADP. Treatment with aspirin $75 \mathrm{mg}$ daily abolished spontaneous platelet aggregation but did not stop her amaurosis fugax. Three other patients including the daughter of AC had hyperaggregable platelets to AA and ADP between attacks of amaurosis fugax and in one case spontaneous aggregation was observed. In one other patient (AM) platelet aggregation was studied 12 hours after an attack but no significant abnormality in platelet aggregation to AA or ADP was found. MH, BM, AM, SB and RS also were treated with 75 or $300 \mathrm{mg}$ aspirin daily but this had no effect on the frequency or duration of their attacks. Platelet release protein assays were all normal apart from in one patient (MH) who subsequently was found to have carcinoma of the cervix.

\section{Discussion}

As previously noted there is a group of young patients with amaurosis fugax who have a favourable prognosis. $^{1-3}$ None of the patients in this group developed symptoms of cerebral or cardiac ischaemia. One patient suffered a permanent sectorial field defect but apart from her attacks sometimes being associated with headache, there were no distinguishing features about her amaurosis fugax. She and one other patient in this group also had attacks of migraine but this may occur in a similar proportion of the general population.

In this series all carotid arteriograms were normal suggesting that this investigation is probably unnecessary in this age group. Similarly, all echocardiograms were normal in these patients although Wilson et al have reported an association between amaurosis fugax and mitral leaflet prolapse. ${ }^{10}$

A relatively high proportion of the patients studied, four out of ten, demonstrated evidence of platelet hyperaggregability compared with normal controls. Two of these had had attacks of uniocular visual loss associated with headache and one later developed carcinoma of the cervix. One patient with platelet hyperaggregability continued to experience amaurosis fugax despite correction of platelet hyperaggregability with aspirin. In five other patients who took aspirin regularly, including two with platelet hyperaggregability, there was no clear effect on the frequency of attacks. Although compliance with treat- 
ment was not confirmed this must cast doubt on the hypothesis that platelet hyperaggregability is the cause of amaurosis fugax in this age group. Unlike Preston et al's patients who seemed to respond to treatment with aspirin and persantin none of these patients had a primary haematological disorder, which may be a reason for the difference in our findings.

\section{References}

1 Marshall J, Meadows S. The natural history of amaurosis fugax. Brain 1968;91:419-34.

2 Poole CJM, Ross Russell RW. Mortality and Stroke after amaurosis fugax. $J$ Neurol Neurosurg Psychiatry 1985;48:902-5.

3 Eadie MJ, Sutherland JM, Tyrer JH. Recurrent monocular blindness of uncertain cause. Lancet 1968;1:
319-21.

4 Preston FE, Martin JF, Stewart RM, Davis-Jones GAB. Thrombocytosis, circulating platelet aggregates and neurological dysfunction. Br Med J 1979;2:1561-3.

5 Couch JR, Hassanein RS. Platelet aggregability in migraine. Neurology 1977;27:843-8.

6 Hanington E, Jones RW, Amess JAL, Wachowicz B. Migraine: a platelet disorder. Lancet 1981;2:720-3.

7 Rabey JM, Vardi Y, Van Dyck D, Streifler M. Ophthalmoplegic migraine: amelioration by flufenamic acid, a prostaglandin inhibitor. Ophthalmologica $1977 ; 175$ : $148-52$.

8 Dougherty JH Jr, Levy DE, Weksler BB. Platelet activation in acute cerebral ischaemia. Lancet 1977;1:821-4.

9 Uchiyama S, Takeuchi M, Osawa M, et al. Platelet function tests in thrombotic cerebrovascular disorders. Stroke 1983;14(4):511-7.

10 Wilson LA, Keeling PWN, Malcolm AD, Ross Russell RW, Webb-Peploe MM. Visual complications of mitral leaflet prolapse. $\mathrm{Br} \mathrm{Med} J$ 1977;2:86-8.

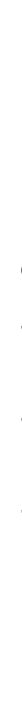

